\title{
Social and Behavioral Determinants of Oral Cancer
}

\section{Eman Allam and Jack Windsor L*}

Department of Oral Biology, Indiana University School of Dentistry, Indianapolis, USA

\begin{abstract}
The association between human behaviors and the development of oral cancer is well recognized. Most oral cancer cases and deaths are due to both individual predisposition linked to specific genetic characteristics and the exposure to carcinogens caused by lifestyle behaviors such as tobacco smoking, betel quid or tobacco chewing, alcohol intake, and micronutrient deficiencies. The purpose of this review was to provide insights into the social and behavioral factors associated with the development of oral cancer. These lifestyle factors and behaviors are considered the downstream determinants of oral cancer, while the upstream determinants are those which are common to all cancers such as the community level environmental factors, industrial pollution and contamination, access to the health care system, health insurance, and quality of health care, which are all dependent on the socioeconomic status of the individual. It was concluded that, since the incidence of oral cancer is greatly impacted by behaviors that can be modified, the impact that these behaviors as well as other social determinants has on oral cancer and its outcome needs to be addressed by society.
\end{abstract}

Keywords: Oral cancer; Behavioral factors; Social determinants

\section{Introduction}

Cancer is generally considered a common cause for mortality worldwide. It is responsible for approximately $20 \%$ of the deaths in developed countries and $10 \%$ in developing countries. It is proposed that there will be about fifteen million new cancer cases and ten million deaths due to cancers annually by 2020 [1]. Oral cancer is the sixth most prevalent cancer type with a global annual incidence of about 270,000 cases and 130,000 deaths [2,3]. Squamous cell carcinoma is the most common type of oral cancer and is frequently associated with two main risk factors, tobacco usage and alcohol intake [4].

Although most of the cases are diagnosed in advanced stages, oral cancers are easily detectable and hypothetically preventable due to their association with well-known risk factors. Tobacco usage and alcohol intake are the two major risk factors and are synergetic. Males are more affected than females. Socioeconomic status has been directly related to the incidence of oral cancer in some reports. Areca nut and tobacco chewing are also strongly associated with oral cancer [4-6]. The highest risk individuals are males in their $50^{\text {th }}$ to $60^{\text {th }}$, who are heavy smokers and alcoholics.

The core question of public health is simply: Why are some populations healthier than others? The question that comes next in priority seems to be: How can diseases be prevented or controlled through the development of appropriate public policies and programs. The development of these appropriate policies and programs depends mainly on the availability of solid scientific evidence recognizing the key social and behavioral variables that when addressed would improve the health of the population and reduce the risk of serious diseases such as oral cancer. Tarlov [7] has defined certain social and behavioral factors that in his opinion would improve the general quality of life, as well as improve the population health dramatically. He summarized these factors into "successful child development, strengthened community cohesion, enhanced self-fulfillment, increased socioeconomic wellbeing, and modulated hierarchical structuring." [7].

\section{Risk Factors and Social Determinants of Oral Cancer}

The most important downstream social determinants related to oral cancer with substantial evidence are tobacco smoking, alcohol usage, tobacco chewing, and dietary micronutrient deficiencies [8]. According to Petti, "Worldwide, $25 \%$ of oral cancers are attributable to tobacco usage (smoking and/or chewing), 7-19\% to alcohol drinking, 10-15\% to micronutrient deficiencies, and more than $50 \%$ to betel quid chewing in areas of high chewing prevalence" [5].

Smoking is currently considered a global epidemic with the tobacco businesses manufacturing five trillion cigarettes per year, which comes out to be about 1000 cigarettes for every individual on earth [9]. About one billion males and 250 million females smoke world-wide, $35 \%$ in developed and $50 \%$ in developing countries. Smokeless tobacco also is common amongst many populations [9]. In the United States, about 7\% of high schoolers are using smokeless tobacco [10].

There is currently sufficient evidence on the relationship between smoking and cancer. In most cases, this relationship is also dosedependent. Epidemiologic data demonstrates that almost one fourth of oral cancer cases are linked to tobacco smoking or chewing. The risk reported in former smokers is much lesser than in current smokers. Individuals that have the habit of alcohol intake and tobacco smoking or chewing consistently are at a higher risk for oral cancer [11-13].

Tobacco products contain more than sixty recognized carcinogens. The carcinogenic activities of those agents mainly occur through the formation of DNA adducts. The most significant carcinogens are the tobacco-specific nitrosamines such as NNK (4-(methylnitrosamino)1-(3-pyridyl)-1-butanone) and NNN (N-nitrosonornicotine), PAH (polycyclic aromatic hydrocarbons), benzo[a]pyrene, and aromatic amines. Among these, the most causally linked carcinogens to oral cancer are NNK, NNN and PAH [11].

From the two billion people using alcohol in the world, about 80 million are diagnosed with alcohol abuse symptoms. The association between heavy alcohol intake and oral cancer is well established. The risk of oral cancer increases with the frequency of alcohol intake. Indeed, among those having 4-5 drinks every day, the risk for oral cancer is estimated to be 2-3 folds higher than in non-drinkers [14-17]. The risk among drinkers is even more when they are tobacco smokers or chewers. Studies have reported that about $7-19 \%$ oral cancer cases are linked to heavy alcohol consumption $[13,18]$.

Ethanol and some other minor components such as polyphenols, acrylamide, and nitrosamines are considered the main carcinogens

*Corresponding author: Jack Windsor L, Department of Oral Biology, Indiana University School of Dentistry, 1121 West Michigan Street, DS 271, Indianapolis IN 46202, USA, Tel: 317-274-1448; Fax: 317-278-1411; E-mail: ljwindso@iu.edu

Received November 16, 2013; Accepted December 24, 2013; Published December 26, 2013

Citation: Allam E (2013) Social and Behavioral Determinants of Oral Cancer Dentistry 4: 182. doi:10.4172/2161-1122.1000182

Copyright: ( 2013 Allam E, et al. This is an open-access article distributed under the terms of the Creative Commons Attribution License, which permits unrestricted use, distribution, and reproduction in any medium, provided the original author and source are credited. 
in alcoholic drinks [17]. Acetaldehyde in specific, the metabolized by-product of ethanol, causes multiple mutagenic effects and thus is considered responsible for the carcinogenic effects of ethanol. This was confirmed through animal and human studies that reported their carcinogenic activity on oral tissues and on epithelial cells [19].

Epidemiological data proved that cultural habits in different countries affect the prevalence of oral cancer. In developing countries, the habit of chewing tobacco and quid is widely shared by both the old and younger male populations. The high incidence of oral cancer in betel-quid chewers was more obvious among the Asian populations. A strong cause and effect relationship was also established among Africans and Indians populations with more prevalence of cheek cancer among betel-quid chewers who do not drink or smoke. In Western countries, a strong association between alcohol drinking habits and increased risk of oral cancer has been reported. For example, alcohol was reported to be the second most important risk factor after smoking according to studies based on the mortality data in North America [20-25].

Hobdell et al. [26] investigated the relationship between socioeconomic status (SES) variables and oral health in an attempt to determine the association between social, economic and behavioral risk factors and the incidence of oral cancer among other oral health concerns. Their results described a marked gradient in oral diseases between the most highly and the least socio-economically developed countries and that there is an apparent association between oral cancer and the SES variables. The results of their study provided evidence that "oral health policies which focus entirely on the genetic and biological determinants of health, leaving the social and societal determinants unaltered, are unlikely to be entirely successful at the level of population health" [26]. The relationship between oral cancer mortality rates and the SES was even reported to be stronger than that for the incidence as indicated from the data on higher mortality rates demonstrated in socially disadvantageous populations in most countries [27].

Attributable risk factors of oral cancer also include diet deficiencies. Global epidemiological data indicates that $30-40 \%$ of cancer cases are associated with unhealthy diets. Case-control studies demonstrated

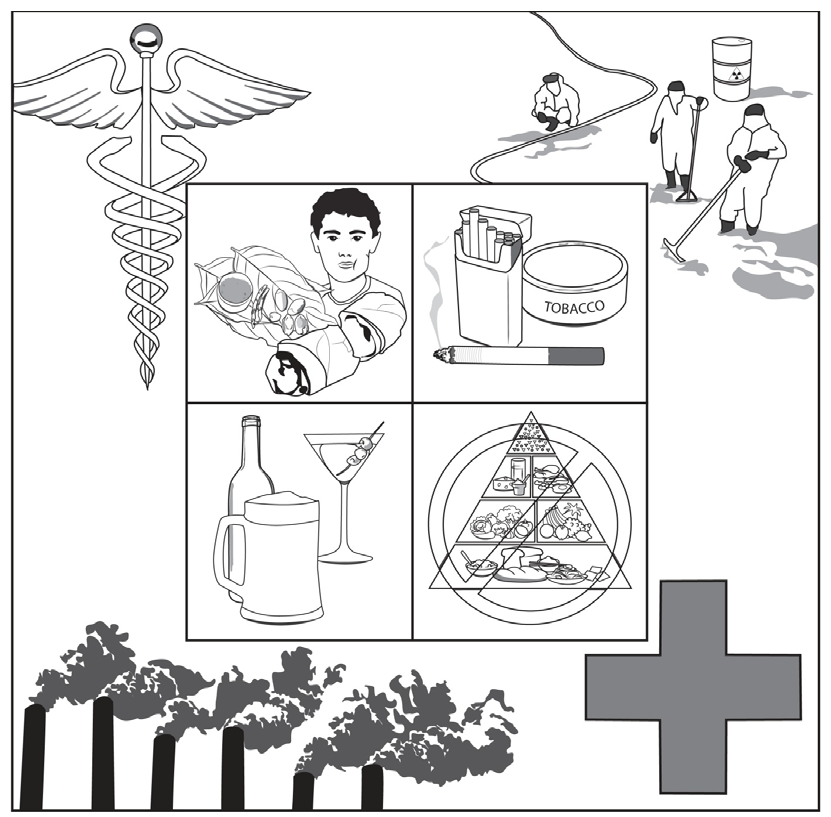

Figure 1: Environmental factors and life-style behaviors impacting oral cancer that oral cancer patients reported histories of diets deficient in fresh fruits and vegetables and those diets rich in vegetables, fruits, fish, and vegetable oils are part of a low-risk diet for oral cancer [28-30]. The mechanisms of action of the dietary factors in cancer development are unclear. However, for oral cancer, it was suggested that fresh foods contain antioxidants and anti-carcinogenic agents such as fibers, flavonoids, carotenoids, vitamins (A, C and E), phytosterols, and folates, which in all might play a vital role in opposing the damaging effects of carcinogens associated with smoking, alcohol drinking or tobacco chewing [31,32]. Behavioral factors that may also be considered with such associations is that individuals at high risk of oral cancer such as heavy smokers, alcoholics, and betel quid chewers generally tend to eat unhealthy diets that is deficient in fresh fruits and vegetables. Thus, the association could be attributable to the simultaneous exposure to synergistic carcinogens [33,34].

The incidence of oral cancer was also reported to be higher in certain occupations and these occupations were described to be risk factors. Workers exposed to formaldhyde, workers in painting and printing jobs, and workers in textile and electronic factories are at increased risk of oral cancer according to data in several studies [8,35-37].

Regarding gender and age factors, studies have reported that oral cancer is more common among men than in women with an approximate ratio of 1.5:1. The risk increases with age and the majority of cases are reported in patients 50 years or older [2]. Johnson et al. found that "male patients are more likely to present at a late stage compared with female patients" [4]. They concluded that "the association between late stage presentation and male gender could reflect gender differences in attitudes towards screening examinations, or differences in willingness to bring symptoms to medical attention." Other studies have attributed the sex differences to more indulgence in risk factors such as smoking, alcohols, and excessive exposure to the sun.

Conway et al. [38] designed a systematic review to address the questions related to the socioeconomic inequalities and oral cancer risk. They set three measures to define socioeconomic status: low income, low occupational social class and low educational attainment. They concluded that low SES was significantly associated with increased oral cancer risk in high- and lower-income countries, across the world, and remained when adjusting for potential behavioral confounders. They stated that, individually, each of the SES measures showed slightly different magnitudes of oral cancer risks and that although some studies had used educational attainment as a measure, the most significant risk of oral cancer was associated with low income. Only four out of the 37 studies included in the study provided data on the association of education with oral cancer risk and they all reported that high educational levels were associated with an increased risk for oral cancer $[38,39]$.

\section{Conclusion}

It can be concluded that oral cancer is mostly attributable to both an individual predisposition or the genetic characteristics and the lifestyle behaviors that are linked to increased risk such as smoking, betel quid or tobacco chewing, alcohol intake, and dietary micronutrient deficiencies. More importantly, the exposure to more than one of these factors has a synergistic effect in increasing the risk of oral cancer. These lifestyle factors and behaviors are considered the downstream determinants of oral cancer, while the upstream determinants are those which are common to all cancers such as the community level environmental factors, industrial pollution and contamination, access to the health care system, health insurance, and quality of health care, which are all dependent on the SES of the individual (Figure 1). 


\section{Recommendation}

Since the incidence of oral cancer is greatly impacted by behaviors that can be modified, the impact that these behaviors as well as other social determinants has on oral cancer and its outcome needs to be addressed by society.

\section{Acknowledgment}

The authors would like to thank Nicole Alderson at the Illustration Department in Indiana University School of Dentistry for her help in preparation of the illustration.

\section{References}

1. Petersen PE (2009) Oral cancer prevention and control-The approach of the World Health Organization. Oral Oncol 45: 454-460.

2. Warnakulasuriya $S$ (2009) Global epidemiology of oral and oropharyngeal cancer. Oral Oncol 45: 309-316.

3. Elias ST, Diniz J, Almeida RS, Alvarenga N, Simeoni LA, et al. (2010) Cytotoxic effect of tobacco extracts on human oral squamous cell carcinoma cell-line. Oral Oncol 46: 869-873.

4. Johnson S, Corsten MJ, McDonald JT, Chun J (2010) Socio-economic factors and stage at presentation of head and neck cancer patients in Ottawa, Canada: A logistic regression analysis. Oral Oncol 46: 366-368.

5. Petti S (2009) Lifestyle risk factors for oral cancer. Oral Oncol 45: 340-350.

6. Cancela M, de Souza DL, Curado MP (2012) International incidence of oropharyngeal cancer: A population-based study. Oral Oncol 48: 484-490.

7. Tarlov AR (1999) Public policy frameworks for improving population health. Socioeconomic status and health in industrial nations - social, psychological and biological pathways. Annals of the New York Academy of Sciences.

8. Llewellyn CD, Johnson NW, Warnakulasuriya KS (2001) Risk factors for squamous cell carcinoma of the oral cavity in young people - a comprehensive literature review. Oral oncol 37: 401-418.

9. Mackay J, Eriksen M (2002) The Tobacco atlas. Geneva: WHO

10. Ranney L, Melvin C, Lux L, McClain E, Morgan L, et al. (2006) Tobacco use: prevention, cessation, and control. Evid Rep Technol Assess 140: 1-120.

11. Hecht SS (2003) Tobacco carcinogens, their biomarkers and tobacco-induced cancer. Nat Rev Cancer 3: 733-744.

12. IARC Working Group on the Evaluation of Carcinogenic Risks to Humans (2004) Tobacco smoke and involuntary smoking. IARC Monogr Eval Carcinog Risks Hum 83: 1-1438.

13. Hashibe M, Brennan P, Benhamou S, Castellsague X, Chen C, et al. (2007) Alcohol drinking in never users of tobacco, cigarette smoking in never drinkers, and the risk of head and neck cancer: pooled analysis in the international head and neck cancer epidemiology consortium. J Natl Cancer Inst 99: 777-789.

14. World Health Organization, Food and Agriculture Organization (2002). Diet, nutrition and the prevention of chronic diseases: report of a joint WHO/FAO expert consultation. WHO, Geneva.

15. World Health Organization (2004) Global Status Report on Alcohol 2004. WHO, Geneva.

16. Seitz HK, Stickel F (2007) Molecular mechanisms of alcohol-mediated carcinogenesis. Nat Rev Cancer 7: 599-612.

17. Baan R, Straif K, Grosse Y, Secretan B, El Ghissassi F, et al. (2007) Carcinogenicity of alcoholic beverages. Lancet Oncol 8: 292-293.

18. Room R, Babor T, Rehm J (2005) Alcohol and public health. Lancet 365: 519 530.

19. Jagerstad M, Skog K (2005) Genotoxicity of heat-processed foods. Mutation Res 574: 156-172.

20. Ikeda N, Handa Y, Khim SP, Durward C, Axell T, et al. (1995) Prevalence study of oral lesions in selected Cambodian population. Comm Dent Oral Epidemiol 25: 49-54.
21. Ikeda N, Ishii T, Lida S, Kawai T (1999) Epidemiological study of oral leukoplakia based mass screening for oral mucosal diseases in a selected Japanese population. Community Dent Oral Epidemiol 19: 160-163.

22. MacFarlane GJ, MacFarlane TV, Lowenfels AB (1996) The influence of alcoho comsumption on world-wide trends in mortality from upper aerodigestive tract cancers in men. J Epidemiol comm health 50: 636-639.

23. Shrestha P, Ikeda N, Fukano H, Takai Y, Moro M (1997) Oral mucosal lesions associated with tobacco and betel-chewing habits: a Nepalese experience. Dent J Malaysia 18: 23-25.

24. La Vecchia C, Tavani A, Franceschi S, Levi F, Corrao G, et al. (1997) Epidemiology and prevention of oral cancer. Oral Oncol 33: 302-312.

25. Zain R (2001) Cultural and dietary risk factors of oral cancer and precancer- a brief overview. Oral Oncol 37: 205-210.

26. Hobdell MH, Oliveria ER, Bautista R, Myburgh NG, Lalloo R, et al. (2003) Ora diseases and socio-economic status (SES). Br Dent J 194: 91-96.

27. Faggiano F, Partanen T, Kogivenas M (1997) Socioeconomic differences in cancer incidence and mortality. IARC sci publ 138: 65-176.

28. Zheng W, Blot WJ, Diamond EL, Norkus EP, Spate V, et al. (1993) Serum micronutrient and the subsequent risk of oral pharyngeal cancer. Cancer Res 53: 795-798.

29. Levi F, Pasche C, La Vecchia C, Lucchini F, Franceschi S, et al. (1998) Food groups and risk of oral and pharyngeal cancer. Int J Cancer 77: 705-709.

30. Franceschi S, Favero A, Conti E, Talamini R, Volpe R, et al. (1999) Food groups, oils and butter, and cancer of the oral cavity and pharynx. $\mathrm{Br} \mathrm{J}$ Cancer 80: 614-620.

31. Bosetti C, Gallus S, Trichopoulou A, Talamini R, Franceschi S, et al. (2003) Influence of the Mediterranean diet on the risk of cancers of the upper aerodigestive tract. Cancer Epidemiol Biomarkers Prev 12: 1091-1094.

32. Boccia S, Cadoni G, Sayed-Tabatabaei FA, Volante M, Arzani D, et al. (2008) CYP1A1, CYP2E1, GSTM1, GSTT1, EPHX1 exons 3 and 4, and NAT2 polymorphisms, smoking, consumption of alcohol and fruit and vegetables and risk of head and neck cancer. J Cancer Res Clin Oncol 134: 93-100.

33. Serdula MK, Byers T, Mokdad AH, Simoes E, Mendlein JM, et al. (1996) The association between fruit and vegetable intake and chronic disease risk factors. Epidemiology 7: 161-165

34. Agudo A, Pera G (1999) Vegetable and fruit consumption associated with anthropometric, dietary and lifestyle factors in Spain. Publ Health Nutr 2: 63-71.

35. Lloyd JW, Decoufle P, Salvin LG (1977) Unusual mortality experience of printing pressman. J Occup Med 19: 543-550.

36. Vagero D, Olin R (1983) Incidence of cancer in the electronics industry: using the new Swedish cancer environment registry as a screening instrument. $\mathrm{Br} \mathrm{J}$ Ind Med 40: 188-192

37. Blair A, Stewart P, O’Berg M, Gaffey W, Walrath J, et al. (1986) Mortality among industrial workers exposed to formaldehyde. J Natl Cancer Inst 76: 1071-1084.

38. Conway DI, Petticrew M, Marlborough H, Berthiller J, Hashibe M, et al. (2008) Socioeconomic inequalities and oral cancer risk: A systematic review and metaanalysis of case-control studies. Int J Cancer 122: 2811-2819.

39. Warnakulasuriya S (2009) Significant oral cancer risk associated with low socioeconomic status. Evid Based Dent 10: 4-5. 